\title{
The characteristics of ambient gases pollutant, South Korea
}

\author{
Amin Kalantarifard, Eun-Song Byeon, Jo Gwanggon, Go Su Yang* \\ Department of Environmental Engineering, Chonbuk National University, Jeonju, South Korea
}

Email address:

Aminkalantarifard@gmail.com (A. Kalantarifard), Gsyang@jbnu.ac.kr (G. S. Yang)

To cite this article:

Amin Kalantarifard, Eun-Song Byeon, Jo Gwanggon, Go Su Yang. The Characteristics of Ambient Gases Pollutant, South Korea. American Journal of Environmental Protection. Vol. 4, No. 1, 2015, pp. 33-39. doi: 10.11648/j.ajep.20150401.15

\begin{abstract}
In this study, DPNH-sampling technique, indophenol method, gas chromatography-flame ionization detector (GCFID) and High performance liquid chromatography were applied to conduct three days continuous measurements in areas of Gunsan city, South Korea to detect the concentration of formaldehyde, acetaldehyde, styrene and ammonia emissions level during $21^{\text {th }}$ to $23^{\text {rd }}$ of October 2012. A total 288 samples were collected at six different locations included residential and industrial areas of the city. The sampling was run in the period of $6 \mathrm{hr}$ for three days. With the combination of local meteorological data, including wind direction and speed, temperature and humidity, the result showed that the concentration of ammonia were higher during the afternoon when temperature increases while the values of formaldehyde, acetaldehyde and styrene were high during the night and early morning. The major source of ammonia, aldehydes and styrene were mainly industries chimney with high average concentration. Highest level of ammonia concentration was detected as $125.8 \mathrm{ppb}$ in the atmosphere during the third day $12 \mathrm{pm}$ when temperature raised to $20.1^{\circ} \mathrm{C}$. The results indicate that in addition the formaldehyde, acetaldehyde and styrene average levels ranged from 3 to $11 \mathrm{ppb}, 1.2$ to $5.6 \mathrm{ppb}$ and 4 to $16.2 \mathrm{ppb}$ during sampling time. This pilot study was undertaken to provide reliable information on distribution patterns of gaseous pollutants in ambient air in Gunsan. The results indicated that the values of emitted pollutants concentration investigated in the present study were below the limits that are mandatory in the South Korea guidelines.
\end{abstract}

Keywords: Gases Emission Level, Local Industrial Park, South Korea

\section{Introduction}

Globally, there is a concern related to the effects of air pollution on the environmental system. The growth of the economy, industrialization and urbanization are identified as major sources of air pollution emissions in developing countries. Several volatile organic compounds (VOCs), including carbonyl compounds (formaldehyde and acetaldehyde), styrene and ammonia have carcinogenic and mutagenic effects on living organisms and the health of humans, and also contribute to promoting photochemical smog. Annually, governments invest huge budgets to measure and monitor the air pollutant emissions to prevent the consequences of these pollutants on the environment and human life.

Formaldehyde and acetaldehyde compounds are ubiquitous in the environment, present in the gaseous, liquid, and particulate phases of the atmosphere [1]. These complex chemical compositions play an important role in the atmosphere, physically and chemically, and also on climate processes or even human health [2]. These compounds are mostly unwanted by-products of many industrial processes especially waste wood combustion. Formaldehyde is the most abundant compound among the emitted aldehydes from wood combustion processes with an emission factor of 422 $\mathrm{mg} / \mathrm{kg}$ of wood while acetaldehyde has lower emission factors of $86.3 \mathrm{mg} / \mathrm{kg}$ of wood [3]. These compounds are stable and lipophilic and can be transported over long distances from their original source when they are released into the atmosphere. The increase of concentration levels of these compounds has become one of the major causes of the degrading air quality in developing countries. These two compounds are known to be irritants of the eye and upper airways, especially the nasal cavity. In addition, formaldehyde can act as a precursor to organic aerosol formation in urban air. 
Styrene $\left(\mathrm{C}_{8} \mathrm{H}_{8}\right)$ is a clear, colorless liquid hydrocarbon which is easily polymerized and therefore widely used in industrial processes such as the manufacturing of plastics, packaging, synthetic rubbers, resins, insulators and also in the production of protective surface coatings [4]. Chronic exposure to styrene emissions can affect the central nervous system causing symptoms such as depression, headache, and fatigue and can cause minor effects on kidney functions and the blood [5]. Styrene is classified by the World Health Organizations International Agency for Research on Cancer (IARC) as a Group 2B carcinogen that is possibly carcinogenic to humans [6,7]. Styrene has been found to be metabolized to styrene-7,8-oxide [8] which is an active metabolite of styrene and classified by the IARC as a Group $2 \mathrm{~A}$ carcinogen that is possibly carcinogenic to humans as well [9].

The emission of ammonia $\left(\mathrm{NH}_{3}\right)$ as a primary gaseous base in the atmosphere is a concern because of its direct contribution to secondary photo- or smog air pollutants, and for its adverse influences on various ecosystems, such as bodies of water and soil [10]. As a component of atmospheric nitrogen $(\mathrm{N})$ deposition, $\mathrm{NH}_{3}$ also plays a role in the cycling of $\mathrm{N}$ in terrestrial and aquatic ecosystems. Some sources of $\mathrm{NH}_{3}$ emissions include chemical industries, food processing, fertilizers, and industrial and publicly owned treatment works. One of the main sources of ammonia identified is uric acid from poultry, which under moist conditions is quickly broken down to urea and then to ammonium-N from which ammonia is released. Ammonia is very soluble in water and readily reacts with other substances in the atmosphere to form ammonium $\left(\mathrm{NH}_{4}{ }^{+}\right)$compounds such as ammonium sulphate which can have profound effects on natural ecosystems. Previous studies indicate that increases of $\mathrm{NH}_{4}{ }^{+}$concentration level in the atmosphere can cause environmental stresses such as soil acidification [11], deforestation [12], and th eutrophication of surface waters $[13,14]$. Therefore, it is necessary to characterize the magnitude and spatiotemporal variability of atmospheric $\mathrm{NH}_{3}$ and $\mathrm{NH}_{4}{ }^{+}$concentrations.

\subsection{Sampling-Site Description}

Gunsan city, with an area of approximately $390.20 \mathrm{~km}^{2}$ and population of 275,298 (2012), is located in the North Jeolla Province of South Korea. The large scale industrialization in the last decade had a major effect on increasing the percentage of emissions formed of different gases in this city. The Gunsan industrial park is located in the northwest with an area of $28.402 \mathrm{~km}^{2}$. Waste wood combustion, chemical materials \& products, plastic manufacturing, food production \& processing, concrete and construction materials production are examples of the current industrial plants in this city. The waste wood combustion power plant located in Gunsan was established in 1990 with an area of $171.816 \mathrm{~m}^{2}$ and represents one of the biggest combustion power plants in the region. Medium density fiberboard (MDF) is a main product by this company. Existing combustion chambers has a maximum burning capacity of 200 tons/day of wood waste. Figure 1 shows the percent distribution of industries in Gunsan city. Over the years, setting the plants in residential neighborhoods of this city has caused a number of problems and extra expenses such as high taxes, local political involvement, and complaints about gaseous pollutants. Since there was no statistical data available for aldehydes, styrene and ammonia emission levels in the area of this city, this study focuses to estimate the concentration level of these pollutants in the atmosphere of Gunsan.

Industrial share overall (Gunsan)

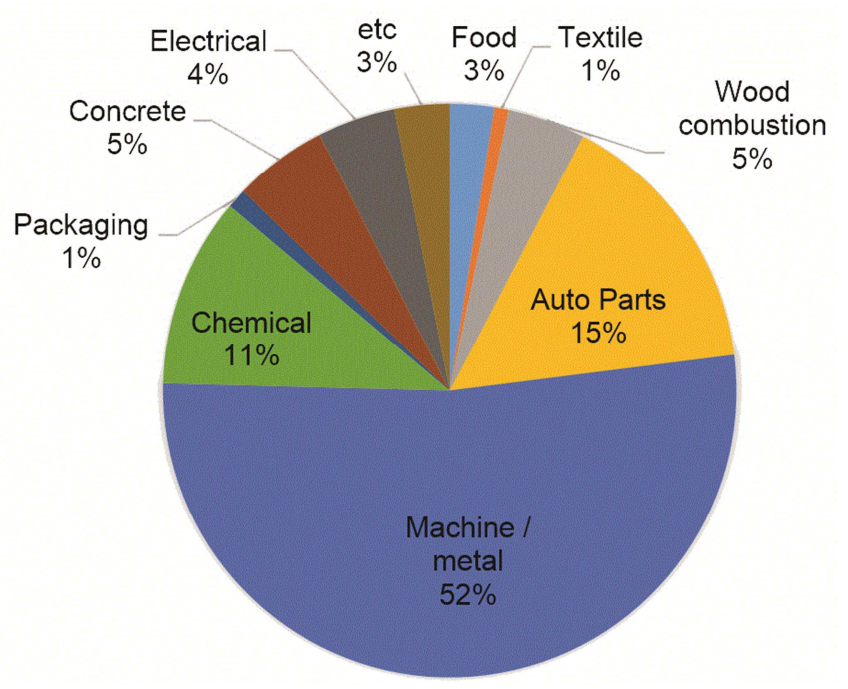

Figure 1. Percent distribution of industries at Gunsan city.

The sampling points were sited to be representative of the air quality in a surrounded area. For this particular research, six total points were selected in the area of Gunsan to provide data within zones and agglomerations where the highest and lowest concentration of pollutants occur during the day and night. The number of sampling points for measurement calculated the base on accounted emission densities, likely distribution patterns of ambient air pollution, and potential exposure. The aldehydes, ammonia and styrene measurements were intially done near the industrial area which were called points A-1 and A-2. The other points were selected in residential area, schools, and the center of the city. A total of 288 samples were collected in the period from the $21^{\text {st }}$ to the $23^{\text {rd }}$ of October 2012 . The sampling was run in the period of $6 \mathrm{hr}$ for three days. Figure 2 shows the photographical image of the Gunsan industrial and residential areas and the location of selected points.

\section{Materials and Methods}

\subsection{Formaldehyde and Acetaldehyde Analysis}

Versapak-bonded C18 cartridges $(360 \mathrm{mg}$ ) purchased from a Top-trading Company in South Korea was used to determine the aldehydes concentration in the atmosphere. The procedure involved the collection of aldehydes samples in $\mathrm{C} 18$ cartridges coated with 2,4-dinitrophenylhydrazine (DPNH) and quantified them using HPLC coupled with a 
UV-Vis detection system at a wavelength of around $360 \mathrm{~nm}$. In the collection procedure, aldehydes were collected from the atmosphere by pumping air into connected cartridges using a personal sampling pump (KEMIK, SARA 5100). The optimum flow rate kept in order to operate the pump stably for at least $10 \mathrm{~min}$ was $2 \mathrm{~L} / \mathrm{min}$, which resulted in a total of $\sim 20 \mathrm{~L}$ of air. Before reaching the cartridges, the air sample passed through the ozone scrubber consisting of a $40 \mathrm{~mm}$ holder containing 1.5 grams of high purity potassium iodide to prevent the oxidation of DPNH by the ozone. After sampling, the end of the cartridge column was closed with a plastic cap, and the cartridges were wrapped individually in aluminum foil and placed in hermetically closed plastic bags and stored in a refrigerator until analysis time. The collection system for aldehydes with the ozone scrubber is shown in Figure 3. The DNPH compound found in the cartridge was slowly eluted with acetonitrile (ACN). The obtained mixed solution (approximately $5 \mathrm{~mL}$ ) of $\mathrm{ACN}$ and aldehydes compounds were kept in the refrigerator for nearly one day to ensure the stability of samples.

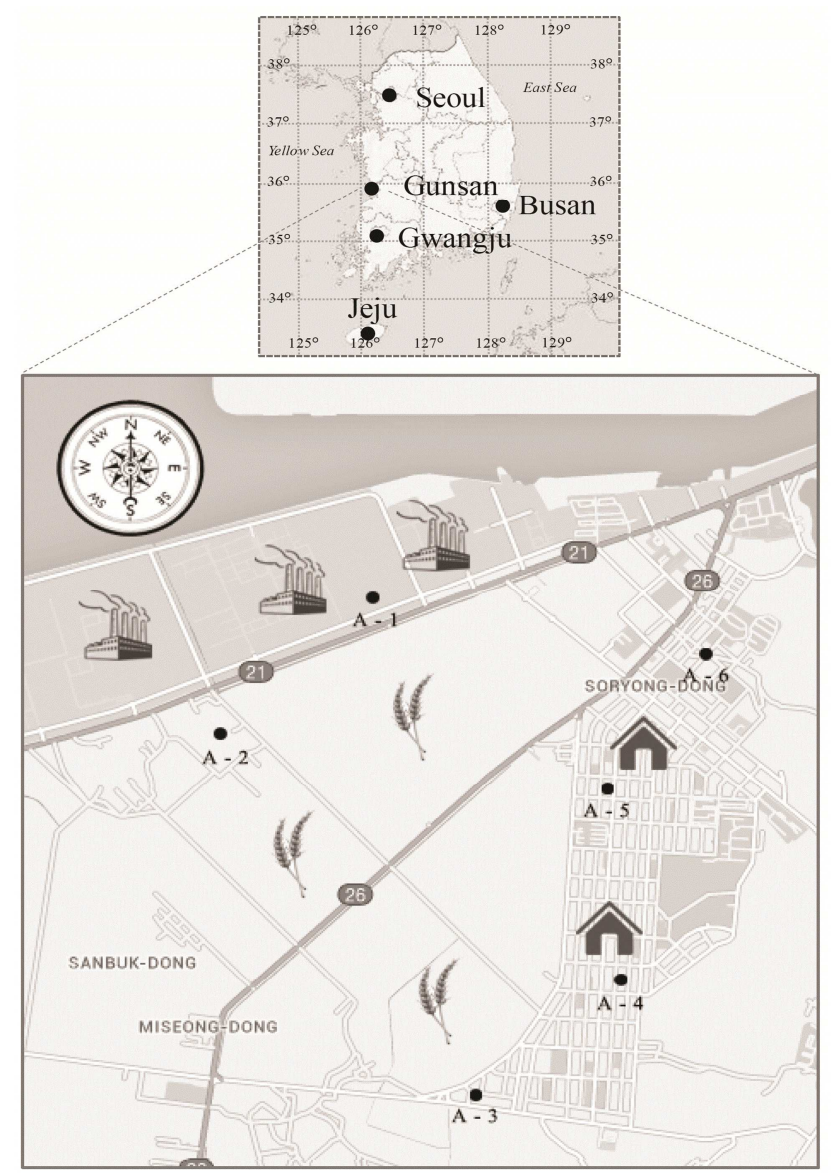

Figure 2. The geographical location of industrial and residential areas at Gunsan and selected air pollution sampling points, A-1 to A-6.

The quantification of aldehyde compounds carried out by HPLC in an Agilent 1100 series capillary liquid chromatography system. The systems consisted of a binary pump, a degasser, an automated injector, a thermo stated column compartment, and a UV-DAD detector. The analytical conditions were as follows: HPLC column dimensions $(250 \mathrm{~mm} \times 4.6 \mathrm{~mm} \times 5 \mu \mathrm{m})$, injection volumes of $10 \mu \mathrm{g}$, a temperature of $35^{\circ} \mathrm{C}$ and mobile phases composed of binary mixtures of ACN and a water flow rate of $1.2 \mathrm{~mL} / \mathrm{min}$. An equilibration time of $1 \mathrm{~min}$ between successive HPLC runs was always adopted. All samples were detected in 360 $\mathrm{nm}$. Aldehydes were identified by retention times, elution order and their absorption spectra. The analytical precision was determined with injections of true standards of formaldehyde and acetaldehyde acquired from (Supelco, USA) an HPLC system to observe retention times and absorption spectras. Collected data from Supelco Company shows the calibration curve for a solution containing true standard formaldehyde and acetaldehyde in concentrations of 14.73 to $14.88 \mu \mathrm{g} / \mathrm{ml}$. These results were compared with chromatogram curves from collected samples to identify the concentration of formaldehyde and acetaldehydes.

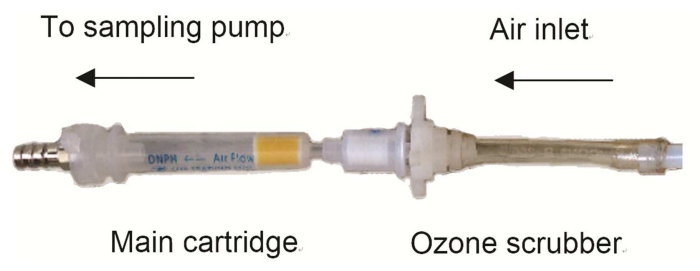

Figure 3. Collection system for aldehydes with ozone scrubber.

\subsection{Styrene}

Styrene in the atmosphere is determined by a capillary column gas chromatography (GC) with a flame ionization detector (FID). Air samples are collected by drawing air using a personal vacuum pump with a flow rate of 0.05 $\mathrm{L} / \mathrm{min}$ for 15 minutes through glass sampling tubes packed with two sections of coconut shell charcoal that has been coated with p-tert-butylcatechol (TBC), which is $10 \%$ by weight. The front section contains $110 \mathrm{mg}$ and the back section contains $55 \mathrm{mg}$ of TBC-coated coconut shell charcoal [15]. After 15 minutes sampling, the samples were removed and tube was sealed with a plastic end cap and sent to the Chonbuk National University laboratory for analysis. In the laboratory, samples are desorbed with toluene and analyzed by $\mathrm{GC}$ using a flame ionization detector. The detailed information about GC-FID experiments, sampling conditions, standard calibration methods and curves can be found in the OSHA analytical manual and NIOSH recommended standards [16].

\subsection{Ammonia}

An ammonia trap system consisted of boric acid bottles in order to trap the emitted ammonia, a variable area flow meter to regulate the flow rate of the sweep-air, a vacuum pump to pull air through the system and a bottle containing silica gel to adsorb the humidity (Figure 4). This method involves capturing ammonia in a boric acid solution and quantifying according to the indophenols-UV method [17]. In our experiment, ammonia absorption in boric acid occurred by vacuuming the ambient air through two bottles containing 25 
milliliters of boric acid $(0.5 \%)$. The vacuum pump was adjusted with a flow rate of $5.0 \mathrm{~L} / \mathrm{min}$ for 10 minutes. The collected samples were buffered at a $\mathrm{pH}$ of 9.5 with a borate buffer in order to decrease the hydrolysis of cyanates and organic nitrogen compounds then finally distilled into a solution of boric acid. Alkaline phenol and hypochlorite react with ammonia to form an indophenol blue that is proportional to the ammonia concentration (EPA Method 350.1) The blue color formed was intensified with sodium nitroprusside and measured by the OPTIZEN $1412 \mathrm{~V}$ spectrophotometer at a wavelength of $640 \mathrm{~nm}$. The calculation of the actual ammonia concentrations in the samples was done using a calibration curve based on an ammonia standard solution.

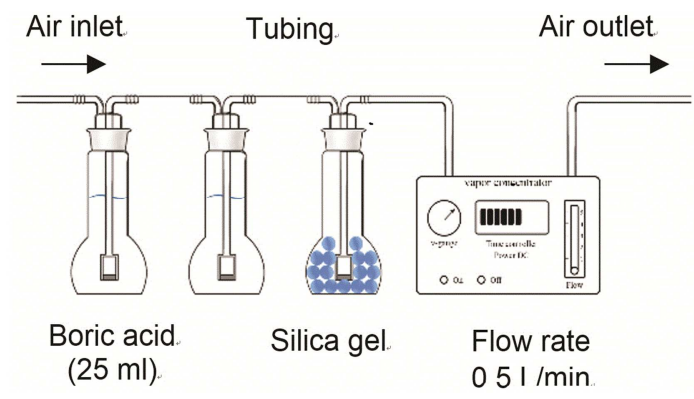

Figure 4. Schematic of ammonia absorption in boric acid.

\section{Results and Discussion}

\subsection{Diurnal Variation of Meteorological Parameters}

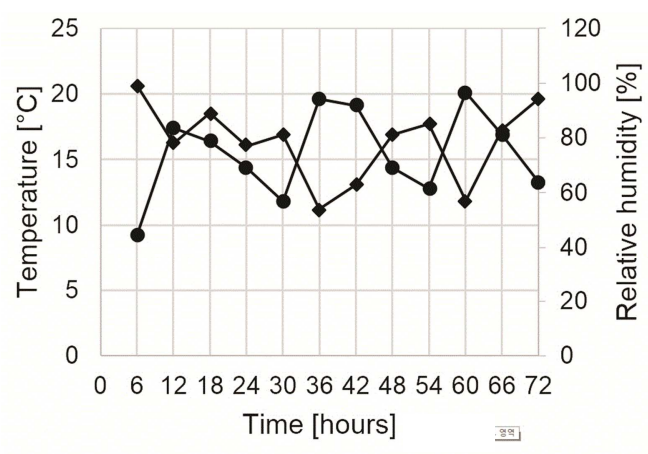

(a) $\rightarrow$ Temperature $\rightarrow$ Humidity

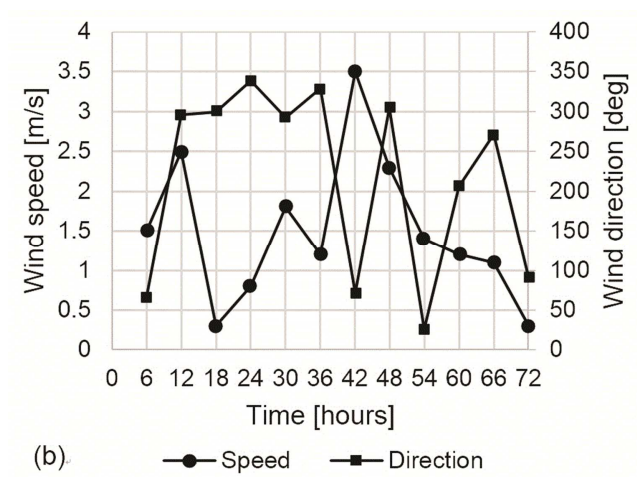

Figure 5. Meteorological conditions recorded during sampling campaign from $21^{\text {th }}$ to $23^{\text {rd }}$ October 2012, the data are 6-h average values. a) relative humidity and temperature, $b$ ) wind direction, wind speed.
The spring and summer climate in Gunsan is hot and humid whereas the fall and winter is cold and dry with local variations due to altitude differences. In 2012 , the seasonal average temperature was $13.5^{\circ} \mathrm{C}$ in spring, $24.1^{\circ} \mathrm{C}$ in summer, $15.3^{\circ} \mathrm{C}$ in fall and $11^{\circ} \mathrm{C}$ in winter. During the sampling period, the highest temperature obtained was on the $23^{\text {rd }}$ with $20.1^{\circ} \mathrm{C}$ and the lowest was $9.3^{\circ} \mathrm{C}$ on the $21^{\text {st }}$. The prevailing wind was a steady $3.5 \mathrm{~m} / \mathrm{s}^{-1}$ with a slight angle across the sea. The wind direction was from the north and northwest in the first and second days and from west to southwest and north to south on the third day of sampling. The meteorological parameters including wind direction, wind speed, relative humidity and temperature were recorded continuously and represented in Figure 5a and b.

\subsection{Diurnal Variation of Formaldehyde, Acetaldehyde and Styrene}

Six hours of average concentrations of pollutants were measured from the $21^{\text {st }}$ to the $23^{\text {rd }}$ of October 2012. The sampling campaign started at 6 am to 12 am each day. The average concentrations of formaldehyde, acetaldehyde and styrene in each location are shown in Table 1. During the studied period, concentrations of acetaldehyde were generally very low and some samples were under the limit of detection while the formaldehyde concentration was higher than the acetaldehyde in all selected areas. The average formaldehyde concentrations remained above $4.3 \mathrm{ppb}$ at point A-1 and A-2 through all three sampling days. There is a consistent underestimation of formaldehyde at $12 \mathrm{pm}$ each day which can probably be attributed to a moisture and temperature effect. The ambient temperature range observed during the sampling period was $9.3-12.8^{\circ} \mathrm{C}$ in the early morning whereas it is increased to $17.4-20.1^{\circ} \mathrm{C}$ at noon. The concentration of formaldehyde generally decreases by increasing the temperature. The average variation of formaldehyde concentrations ranged from 3 to $11 \mathrm{ppb}$ and acetaldehyde concentrations from 1.2 to $5.6 \mathrm{ppb}$ (Table 1).

Table 1. The average gases concentrations (ppb) in each location during sampling period

\begin{tabular}{lllll}
\hline Locations & & Day 1 & Day 2 & Day 3 \\
\hline \multirow{4}{*}{ A-1 } & formaldehyde & 11 & 8.3 & 4.4 \\
& acetaldehyde & 5.6 & 3.2 & 2.6 \\
& styrene & 16.2 & 11.9 & 6.5 \\
A-2 & formaldehyde & 8 & 5 & 4.3 \\
& acetaldehyde & 3.2 & 3 & 2.4 \\
& styrene & 12.5 & 9.3 & 7 \\
A-3 & formaldehyde & 4.5 & 3 & 3.8 \\
& acetaldehyde & 3 & 1.2 & 2.1 \\
& styrene & 5.6 & 4.7 & 4 \\
A-4 & formaldehyde & 5.2 & 4.4 & 3.3 \\
& acetaldehyde & 3.3 & 2.4 & 2.7 \\
& styrene & 8.2 & 7.9 & 5.05 \\
A-5 & formaldehyde & 4.8 & 4.7 & 3.9 \\
& acetaldehyde & 2.4 & 2.4 & 2.2 \\
& styrene & 8.5 & 8.2 & 6.2 \\
A-6 & formaldehyde & 6.2 & 5.1 & 4 \\
& acetaldehyde & 3.5 & 3.8 & 2.2 \\
\hline
\end{tabular}


The highest concentration level of formaldehyde was obtained during the first day at night when the temperature and humidity was recorded as $14.4^{\circ} \mathrm{C}$ and $77 \%$ while the highest level of acetaldehyde was obtained during the first morning when the humidity was recorded as $99 \%$. Figure 6 shows the continuously measured $6 \mathrm{~h}$ average values of formaldehyde, acetaldehyde and styrene in all selected locations. The lower concentrations of formaldehyde and acetaldehyde at points A-3 to A- 6 could be the result of a longer distance from industrial sections which possibly decrease the pollutants emission level. In general, based on the time of sampling, similar patterns for the concentration level of formaldehyde and acetaldehyde were observed each day. During this monitoring period, the highest average styrene concentration observed for day one was $16.2 \mathrm{ppb}$ and the lowest instantaneous level was $4 \mathrm{ppb}$ on the third day. The highest recorded concentrations of airborne styrene were measured at point A-1 and A-2, which are at a very close proximity to the industrial area. The residential area located in the south and southwest was only impacted slightly by the styrene emissions and only when the winds were from the southwest.
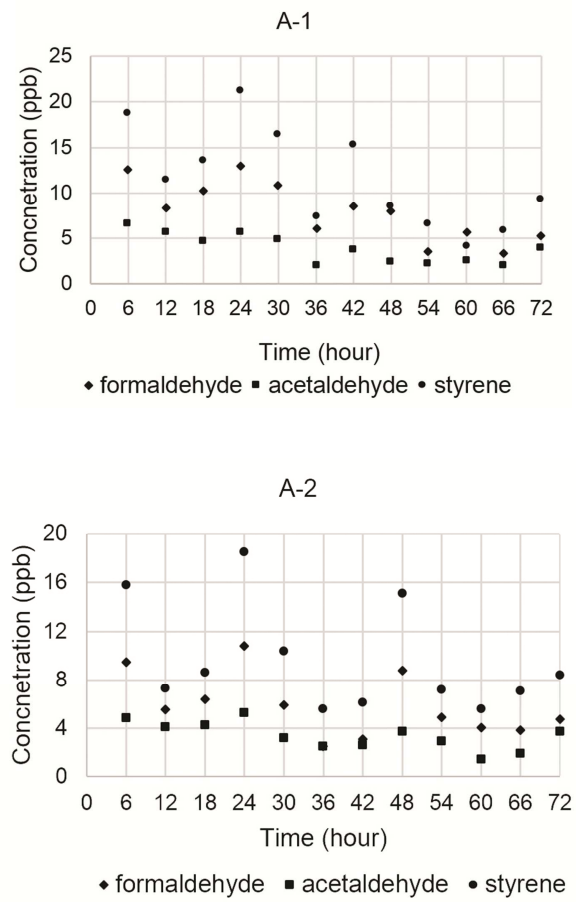

A-3

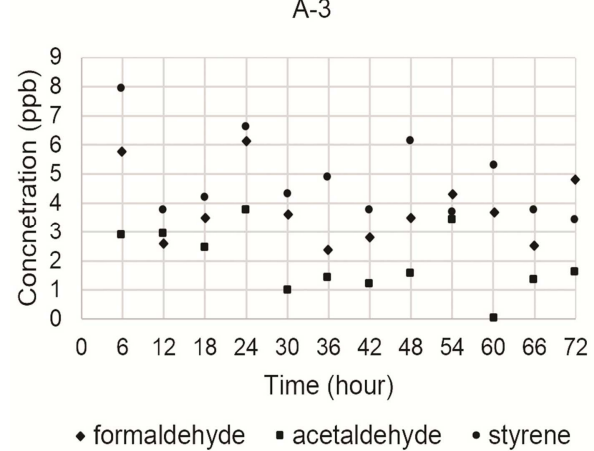

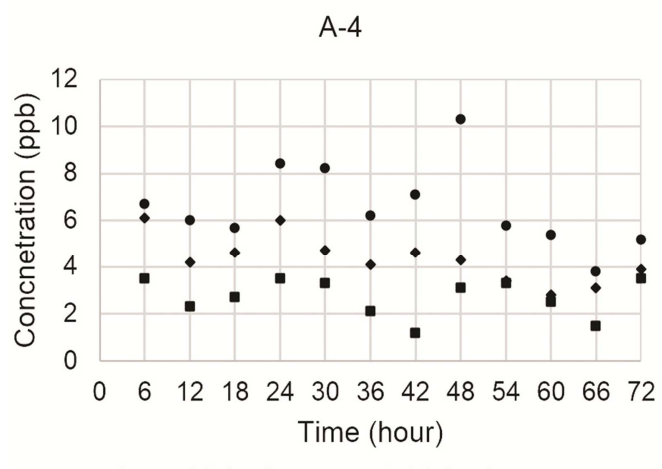

- formaldehyde - acetaldehyde • styrene

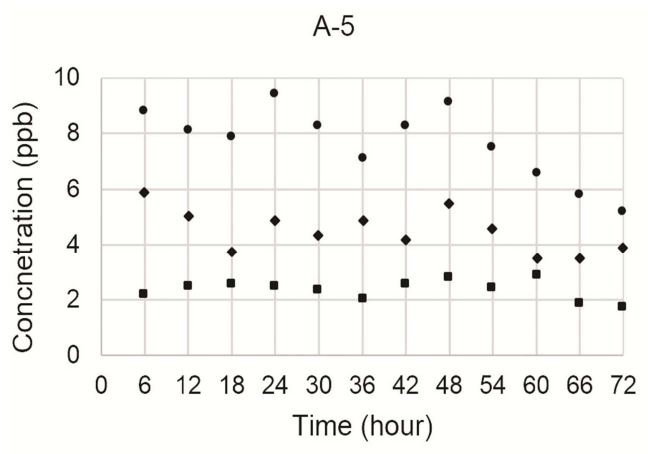

- formaldehyde - acetaldehyde • styrene

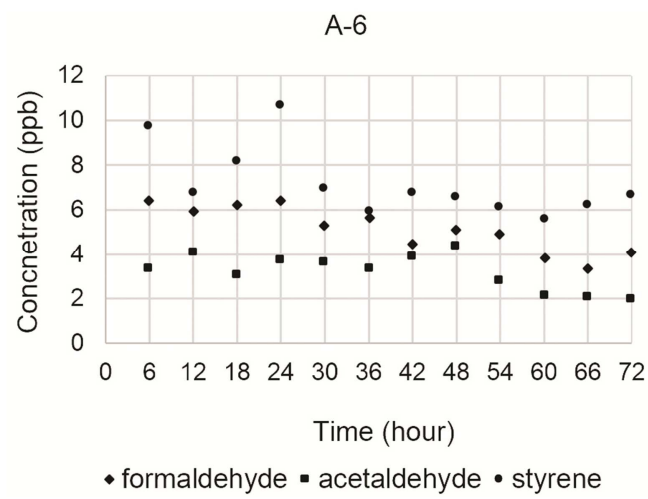

Figure 6. Continuously measured 6-h average values of formaldehyde acetaldehyde and styrene in all selected locations from $21^{\text {th }}$ to $23^{\text {rd }}$ October 2012 .

\subsection{Diurnal Variation of Ammonia}

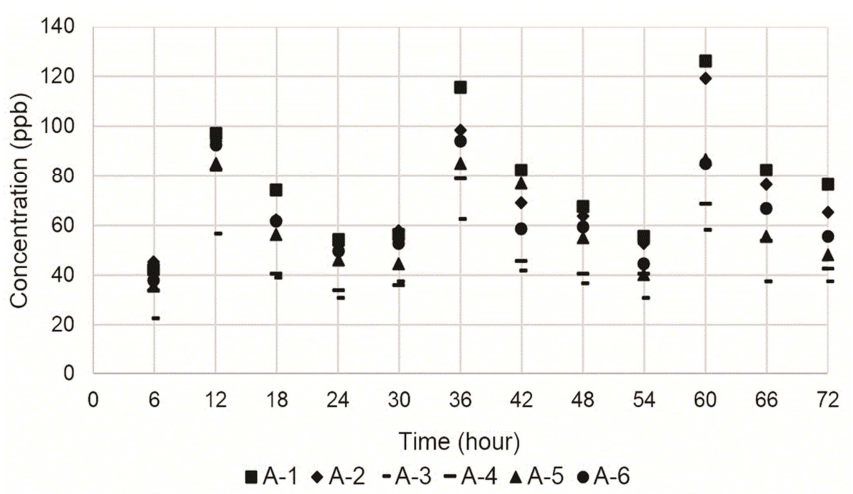

Figure 7. Daily variation of ambient ammonia concentrations in all selected locations at Gunsan. 
Figure 7 represents the daily variation of ambient $\mathrm{NH}_{3}$ concentrations at the six sampling locations. In Gunsan, the relative mean temperature level at $12 \mathrm{pm}$ was approximately 1.3 times higher than the mean level for 12 am as is showed in Figure 5a. The concentration of ammonia generally increased when temperature increased. Figure 7 shows that the mean $\mathrm{NH}_{3}$ levels in Gunsan ranged from 22.5 to 57.8 $($ mean $=40.1 \mathrm{ppb})$ at $6 \mathrm{am}, 56.6$ to $125.8 \mathrm{ppb}($ mean $=91.2$ $\mathrm{ppb})$ at $12 \mathrm{pm}, 37.4$ to $82.3 \mathrm{ppb}($ mean $=59.8 \mathrm{ppb})$ at $6 \mathrm{pm}$, and from 30.4 to 76.5 (mean $=53.4 \mathrm{ppb}$ ) at $12 \mathrm{am}$, respectively. For all the sampling durations, the highest level of $125.8 \mathrm{ppb}$ was obtained on the third day at $12 \mathrm{pm}$ at point A-1. To discern the difference between sampling times, the mean average $\mathrm{NH}_{3}$ concentrations at the highest level at 12 pm was divided by the mean $\mathrm{NH}_{3}$ concentration at 6 am. The mean ratios were $2.2,2.0,1.9,2.1,2.14$ and 2.0 in location A-1 to A-6 respectively. However, the ratio of 2.2 in locations A-1 is the biggest number which indicates that there is either an increased emission under the same sources, or there is a new emission source during the daytime. At this stage, one explanation for the higher emission level of $\mathrm{NH}_{3}$ in the location A-1 is a close distance to chemical industries which has a significant impact on the overall elevation of ammonia in the area.

\subsection{Influence of Surrounding Areas and Wind Direction}

The industrial sites in Gunsan are located about 500-1000 meters away from the sea in the northwest. High concentrations of primary aldehydes and ammonia pollutants generated from these manufacturing processes during the day and night is a main cause of the increasing concentration levels of harmful gases in Gunsan. These pollutants are usually transported to the residential areas with the aid of the sea breeze. Therefore, a distribution of pollutants by sea and land breezes significantly affects the actual pollutant concentration levels in selected sampling locations in this study. Taking a close look at the effect of wind direction on formaldehyde, acetaldehyde and styrene dispersion data during the campaign, the wind direction was from north and northwest (from the sea) during the first two days (Fig. 5b) while on the $3^{\text {rd }}$ day, the wind was blowing from the west and northeast. Weak

Previous research has reported a seasonal cycle in ambient $\mathrm{NH}_{3}$ concentrations $[18,19]$ with maximum concentrations occurring during warm days. This seasonal cycle in ambient concentrations is in agreement with the temperature dependence of aqueous-phase partitioning between $\mathrm{NH}_{3}$ and $\mathrm{NH}_{4}{ }^{+}$, as well as the equilibrium between aqueous-and gas phase $\mathrm{NH}_{3}$ as predicted by Henry's law, which results in increasing ammonia emissions from the emission sources [20,21]. Recorded results shows the concentrations of $\mathrm{NH}_{3}$ reach a maximum at $12 \mathrm{pm}$ on the third day when the temperature rose to $20.1^{\circ} \mathrm{C}$ at all sites whereas the minimum concentration was observed during the first day morning of sampling when the temperature was $9.3^{\circ} \mathrm{C}$. winds with a speed of $0.3 \mathrm{~m} / \mathrm{s}$ and $0.8 \mathrm{~m} / \mathrm{s}$ were during the evening of the $1^{\text {st }}$ day, which increased to more than $3 \mathrm{~m} / \mathrm{s}$ during the $2^{\text {nd }}$ day.
Formaldehyde and acetaldehyde concentration levels increased with the decreased wind speed. On the first day, the concentration level of formaldehyde, acetaldehyde and styrene were recorded as $12.9,5.7$ and $21.2 \mathrm{ppb}$ at $12 \mathrm{am}$ in point A-1 when the wind speed dropped to $0.8 \mathrm{~m} / \mathrm{s}$. In addition, Figure 5a shows that the temperature dropped from 17.4 at $12 \mathrm{pm}$ to 14.4 at $12 \mathrm{am}$. The decreased temperature at midnight is another factor which caused an increase of these pollutant levels during the sampling time.

The highest pollutant levels were expected for all sampling points at 6 am during the first day since the lowest temperature, highest humidity and lowest wind speed had been recorded. However, as is shown in Figure 5b, wind direction was from the northeast to the southwest during this time which significantly reduced the emission concentration levels of all selected sampling points. At point A-1, we measured the concentration of formaldehyde, acetaldehyde and styrene as $12.51 \mathrm{ppb}, 6.63 \mathrm{ppb}$ and $18.8 \mathrm{ppb}$ at 6 am that we believe is lower than the actual concentration level of pollutants at this time.

\section{Conclusion}

The importance, in a South Korean context, to estimate and assess the concentration levels of gaseous pollutants from industrial power plants, agriculture and livestock as an environmental impact has become an increasing concern to public and private sectors. The acceptable levels of acetaldehyde, ammonia and styrene in South Korea have been continuously reduced in the past decade. South Korea's ministry of environment (MEV) announced in January 2010 that it had settled the suit by agreeing to implement performance standard limits for acetaldehyde as $0.05 \mathrm{ppm}$, ammonia as $1 \mathrm{ppm}$ and styrene as $0.4 \mathrm{ppm}$ for a 24 hour average value in residential areas. According to this agreement there is no standard limit for formaldehyde in the atmosphere but there is an indoor standard limit value as 0.12 $\mathrm{mg} / \mathrm{m}^{3}$.

The overall results of this continuous measurement of gaseous pollutants shows that the industrial area of Gunsan is clearly a source for generated criteria pollutants. The correlation between meteorological data, especially air direction and pollutant levels, shows during the time that air direction is from the west and northwest to the east and southeast (from industrial area to residential), higher concentration levels at selected points have been recorded. In general, a higher concentration of ammonia was recorded at above $125 \mathrm{ppb}$ during the third day $(12 \mathrm{pm})$ at point $\mathrm{A}-1$ when the average temperature rose to $20.1^{\circ} \mathrm{C}$. The results indicate that the formaldehyde, acetaldehyde and styrene levels ranged from 3 to $11 \mathrm{ppb}, 1.2$ to $5.6 \mathrm{ppb}$, and 4 to 16.2 ppb during sampling times.

The obtained result in this research showed that the highest emission values of pollutants during sampling in the residential areas of Gunsan are still much lower than standard limits. Measurements of pollutants such as aldehydes and ammonia are often limited by the non-availability of feasible 
techniques for online analysis. In this study, measurements of pollutants have been done during October, which is considered autumn in South Korea. We believe seasonal experiments should be considered in the future to obtain the representative data of pollutant concentrations in this city.

\section{Acknowledgements}

This work was supported financially by the climate change specialization graduate school of Chonbuk National University.

\section{References}

[1] Oliveira, F.S., E.L. Sousa, and J.B. Aderade, 2007: Sensitive flow analysis system for the fluorimetric determination of low levels of formaldehyde in alcoholic beverages. J. Talenta, 73, 561-566.

[2] Beiner, K., A. plewka, S. Haferkorn, Y. linuma, W. Engewald, and H. Hermann, 2009: Quantification of organic acids in particulate matter by coupling of thermally assisted hydrolysis and methylation with thermodesorption-gas chromatographymass spectrometry. J. Chromatography A, 1216, 6642-6650.

[3] Hedberg, E., A. Kristensson, M. Ohlsson, C. Johansson, P.A. Johansson, E. Swietlicki, V. Vesely, U. Wideqvist, and R. Westerholm, 2002: Chemical and physical characterization of emissions from birch wood combustion in a wood stove. J. Atmospheric Environment, 36, 4823-4837.

[4] Chen, Q. F., R. K. Milburn, and N.S. Karellas, 2006: Real time monitoring of hazardous airborne chemicals: A styrene investigation. J. Hazardous Materilas, 132, 261-268.

[5] U.S. Environmental Protection Agency, 2006: Health and Environmental Effects Profile for Styrene. Washington, DC, ECAO/CIN. 103pp.

[6] IARC (International Agency for Research on Cancer), 2002: Styrene. World Health Organization, Lyon. IARC monographs on the evaluation of the carcinogenic risks to humans. 82, 437-550pp.

[7] ATSDR (Agency for Toxic Substances and Disease Registry), 2007: Toxicological profile for styrene (draft for Public Comment). US Department of Public Health and Human Services, Public Health Service. Atlanta, GA. 140.Available: http://www.atsdr.cdc.gov/ToxProfiles/tp53.pdf.

[8] Guengerich, F.P., D.H. Kim, and M. Iwasaki, 1991: Role of human cytochrome P450 IIE1 in the oxidation of many low molecular weight cancer suspects. J. Chemical Research in Toxicology, 4, 168-179.
[9] IARC (International Agency for Research on Cancer), 1994: IARC monographs on the evaluation of carcinogenic risk to humans. Some Industrial Chemicals. 60, 233-320pp.

[10] Hsieh, L. T., and T. C. Chen, 2010: Characteristics of ambient ammonia levels measured in three different industrial parks in Southern Taiwan. J. Aerosol and Air Quality Research, 10, 596-608.

[11] Roelofs, J. G. M., A. J. Kempers, A. L. F. M. Houdijk, and J. Jansen, 1985: The effect of airborne ammonium sulphate on Pinusnigra var. maritima in the The Netherlands. J. Plant and Soil, 84, 45-56.

[12] Nihlgard, B., 1985: The ammonium hypothesis-an additional explanation to the forest dieback in Europe, J. Ambio, 14, 2-8.

[13] Paerl, H.W., 1995: Coastal eutrophication in relation toatmospheric nitrogen deposition: current perspectives. J. Ophelia, 41, 237-259.

[14] Paerl, H.W., and D. R. Whitall, 1999: Anthropogenically derived atmospheric nitrogen deposition, marine eutrophication and harmful algal bloom expansion: is there a link?. J. Ambio, 28, 307-311.

[15] OSHA (Analytical Methods Manual), 1990: U.S. Department of Labor, Occupational Safety and Health Administration. Method 9 - Styrene, American Conference or Government Industrial Hygienists (ACGIH); Cincinnati, OH-No. 4542.

[16] NIOSH, Criteria for a Recommended Standard, 1983: Occupational Exposure to Styrene, U.S. Department of Health and Human Services, Public Health Service, Center for Disease Control, National Institute for Occupational Safety and Health, Cincinnati, OH-No. 83-119.

[17] Kawashima, S., and S. Yonemura, 2001: Measuring ammonia concentration over a grassland near livestock facilities using a semiconductor ammonia sensor. J. Atmo Envir, 35, 3831-3839.

[18] Robarge, W. P., J. T. Walker, R. B. McCulloch, and G. Murray, 2002: Atmospheric concentrations of ammonia and ammonium at an agricultural site in the southeast United States. J. Atmospheric Environment, 36, 1661-1674.

[19] Roelofs, J. G. M., A. J. Kempers, A. L. F. M. Houdijk, and J. Jansen, 1985: The effect of airborne ammonium sulphate on Pinusnigra var. maritima in the The Netherlands. J. Plant and Soil, 84, 45-56.

[20] Asman, W. A. H., M. A. Sutton, and J. K. Schjorring, 1998: Ammonia: emission, atmospheric transport, and deposition. J. New Phytologist, 139, 27-48.

[21] Ni, J., 1999: Mechanistic models of ammonia release from liquid manure: a review. J. Agricultural Engineering Research, $72,1-17$. 